\title{
The Global Scope of Sudden Cardiac Death
}

\author{
Ferrer Marrero Daisy ${ }^{1 *}$ and Ochoa Montes Luis Alberto ${ }^{2}$ \\ ${ }^{1}$ Havana Medical University, Cuba \\ ${ }^{2}$ Hermanos Ameijeiras Hospital, Havana, Cuba \\ *Corresponding author: Ferrer Marrero Daisy, Hermanos Ameijeiras Hospital, Havana, Cuba
}

Received: 眥 July 13, 2020

Published: 㭗 July 28, 2020

Keywords: Sudden death; Sudden cardiac death; Cardiovascular disease

\section{Opinion}

Frequently there are people who, directly or indirectly, have suffered the loss of a loved one in circumstances that make it more surreal and painful; There are instances of individuals who, being well, on the street, will abruptly fall to the ground and cannot receive medical assistance; or that being young, healthy and strong, like some athletes, die without previous signs, leaving behind an impact of recognized importance on their friends and family. This phenomenon or process, known as sudden death (SD), as it occurs, is characterized by being a natural type of death, as it is not related, in its cause, to any violent event; it is unexpected in its presentation and it is quick in its installation, since it takes a short period of time from the start of the demonstrations, if any, to the diagnosis and certification of death. Sudden death can be related to diseases that cause it by affecting various systems; in the case of sudden cardiovascular death (SCVD) it is a natural death from cardiac causes, preceded by sudden loss of consciousness, which typically occurs within 1 hour after onset of acute symptoms, in an individual who is known to present a pre-existing heart disease, known or not by the patient, but in which the time and mode of death are unexpected. In the case of not being witnessed (it occurs in two thirds of the cases) it is considered sudden if the victim was seen alive 24 hours prior to the event. If life is maintained thanks to the use of artificial devices, the time from the moment of putting the patient under these supports is considered [1].

It appears, as a recognized entity, in the International Classification of Diseases and Health-Related Problems (ICD10), under different codes: (I.46.1: Sudden cardiac death, thus described; R95: Sudden infant death syndrome, (R96: Other sudden deaths of unknown cause) and represents, according to experts, one of the main challenges for healthcare systems in this century, this statement is justified by its high incidence [2]. It is known that cardiovascular deaths in global statistics represent an important cause of death worldwide, affecting age groups and gender [3]. But in the case of the SCVD, such is its magnitude that between 4 and 5 million events occur annually worldwide which means 10 events for every minute spent reading these lines [4]. In the United States, the SCVD becomes the first victimizer of the population, causing 400,000 deaths annually, with an incidence that exceeds deaths caused by cerebrovascular diseases, lung cancer, HIV-S IDA infection and breast cancer, just for name a few ones 1. In Cuba, based on the research work carried out during the last 25 years by the Research Group on Sudden Death (GIMUS) and the information published by the statistical yearbook of the Ministry of Public Health (MINSAP), is estimated the occurrence of 8021 sudden events, for 2019 which means 2 deaths per day and 1 episode every 65 minutes, with a rate of $71.6 \times 100,000$ inhabitants representing a $7.8 \%$ of natural deaths in that year [5]. But the great impact of the figures presented, has added by an element of a family, social and economic nature that transcends the personal sphere; is about the drama in its presentation, since it constitutes an important cause of years of life potentially lost when the event occurs abruptly, in subjects, often young, apparently healthy, in working-age groups [6].

Another element to consider in the approach to the global nature of the SCVD lies in aspects that clearly make it difficult for the scientific community to do projections (despite not escaping to any region of the world with that high number of deaths), including 
data and studies that make it possible to standardize the analyzes and the actions, since there is no total consensus regarding its definition and which is worse, although derived from its statistical registry. Special mention for the need to standardize the study of the marker, predictor and triggering factors that exist as well as that of coronary arterial disease, due to their etiological importance in this death [7].

The treatment of this health problem worldwide, based upon its etiopathogenical complexity and the diversity of population groups in which it occurs, goes beyond the field of study of any particular discipline, based on the fact that the relationship between disciplines in medicine is part of the disciplinary interaction between the sciences. This unquestionably leads us to Piaget, who points out that "interdisciplinarity ceases to be a luxury or an occasional product to become the very condition of progress" [6]. The complex nature of the problems currently facing the medical, science requires coherence of the knowledge - based on an interdisciplinary approach of problems from different areas of expertise to achieve their solution. This is a great challenge to face SCVD, resort to interdisciplinarity, which must be seen and understood as a process that allows to resolve controversies, exchange criteria, collate and evaluate contributions, integrate data and even reach new definitions; thus interdisciplinary cooperation is ultimately the rational alternative for addressing this and other issues, which go beyond the limits of traditional specialties.

An increase in the incidence and prevalence of cardiovascular diseases in the coming decades worldwide, forces us to review the current approaches from all the aforementioned aspects, without ever renouncing the strength that intersectorality represents. The circumstances surrounding intersectorality in the health sector are, to a large extent, present in the theoretical and practical approach that is needed to deal with sudden death; the gap between them is difficult to navigate, since in the first place it is necessary to achieve a clear definition by the health sector of the specific weight that each sector has in the epidemiological situation as a consequence and result, in order to properly insert them into the strategy and action plan, through programs and projects. The domain that the health sector has of the problem and its solutions is vital to achieve the participation of the other sectors, in addition to bearing in mind the importance of the participation of the sectors from the beginning, in the identification of problems in order to achieve a comprehensive reaction to them.

Here is the great challenge.

\section{References}

1. Myerburg RJ, Castellanos A (2008) Cardiovascular Collapse, Cardiac Arrest, and Sudden Cardiac Death. In: Fauci AS, Braunwald E, Kasper DL, Hauser SL, Longo DL, Jameson JL, et al., (eds). Harrison's, Principles of Internal Medicine. $17^{\text {th }}$ edn. New York: Mc Graw-Hill: p. 282-288.

2. Organización Mundial de la Salud Organización (2020) Panamericana de la Salud. Clasificación Estadística Internacional de Enfermedades y Problemas relacionados con la Salud. 10a ed. Washington, USA.

3. GA Roth, MH Forouzanfar, AE Moran, Andrew E Moran, Ryan Barber, et al. (2015) Demographic and epidemiologic drivers of global cardiovascular mortality. N Engl J Med 372: 1333-1341.

4. Ochoa LA, González M, Vilches E, Fernández Rodríguez JE, et al. (2014) Muerte súbita cardiovascular en poblaciones de riesgo. CorSalud.

5. Ministerio de Salud Pública (2020) Anuario estadístico de salud 2019 [Internet]. La Habana: MINSAP, Dirección Nacional de Registros Médicos y Estadísticas de Salud.

6. Ochoa-Montes L, Araujo-González R, Ferrer-Marrero D (2018) La muerte súbita cardiovascular en su devenir entre interdisciplinariedad e intersectorialidad. Medisur 16 (5).

7. Ochoa Montes LA (2017) Muerte súbita cardiovascular: un desafío actual. Editorial. Revista Cubana de Medicina 56 (1).

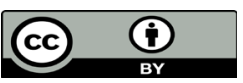

This work is licensed under Creative Commons Attribution 4.0 License

To Submit Your Article Click Here: Submit Article

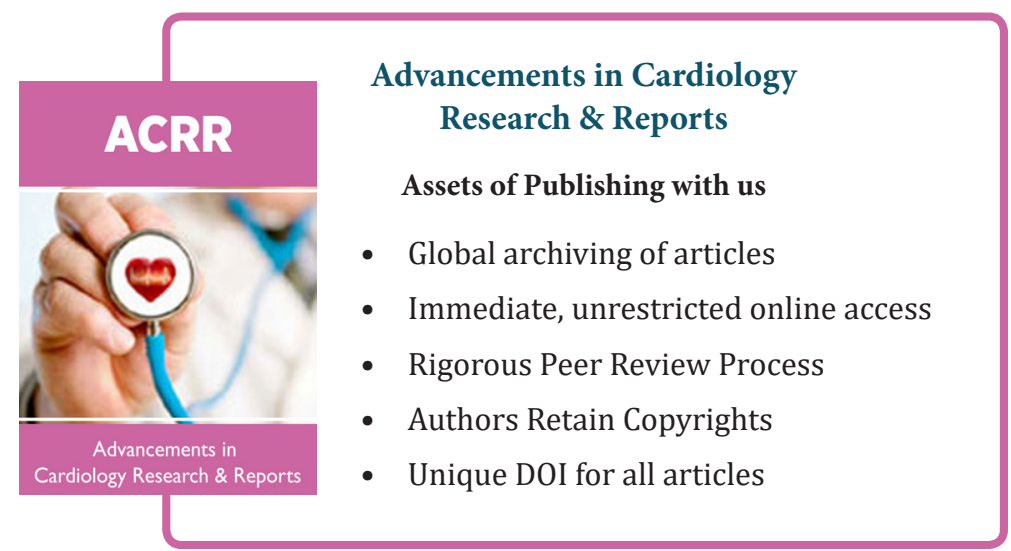

